\title{
Bonding of universal adhesives to dentin - old wine in new bottles?
}

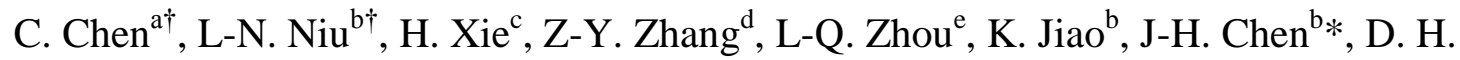
Pashley ${ }^{\mathrm{f}}$, F. R. Tay ${ }^{\mathrm{g} *}$

ajiangsu Key Laboratory of Oral Diseases, Nanjing Medical University; Department of Operative Dentistry \& Endodontics, Affiliated Hospital of Stomatology, Nanjing Medical University, Nanjing, Jiangsu, China

${ }^{\mathrm{b}}$ State Key Laboratory of Military Stomatology, Department of Prosthodontics, School of Stomatology, Fourth Military Medical University, Xi'an, Shaanxi, China

${ }^{\mathrm{c}}$ Jiangsu Key Laboratory of Oral Diseases, Nanjing Medical University; Department of Prosthodontics, Affiliated Hospital of Stomatology, Nanjing Medical University, Nanjing, Jiangsu, China

${ }^{\mathrm{d}}$ Department of Prosthodontics, School \& Hospital of Stomatology, Zhejiang University, Hangzhou, Zhejiang, China

${ }^{\mathrm{e}}$ The State Key Laboratory Breeding Base of Basic Science of Stomatology (Hubei-MOST) \& Key Laboratory for Oral Biomedical Ministry of Education, School \& Hospital of Stomatology, Wuhan University, Wuhan, Hubei, China

${ }^{\mathrm{f}}$ Department of Oral Biology, Georgia Regents University, Augusta, Georgia, USA ${ }^{\mathrm{g}}$ Department of Endodontics, Georgia Regents University, Augusta, Georgia, USA

\section{${ }^{\dagger}$ Equal contributors}

*Corresponding authors: Dr. Franklin Tay: Department of Endodontics, College of Dental Medicine, Georgia Reagents University, Augusta, GA, USA; Email: ftay@gru.edu; Tel.: +1 706721 2033; Fax: +1 706721 6252; Dr. Ji-hua Chen: State Key Laboratory of Military Stomatology, School of Stomatology, Fourth Military Medical University, Xi'an, China; Email: jhchen@fmmu.edu.cn; Tel.: +86029 84776001 


\section{ABSTRACT}

Objective: Multi-mode universal adhesives offer clinicians the choice of using the etch-and-rinse technique, selective enamel etch technique or self-etch technique to bond to tooth substrates. The present study examined the short-term in vitro performance of five universal adhesives bonded to human coronal dentin. Methods: Two hundred non-carious human third molars were assigned to five groups based on the type of the universal adhesives (Prime\&Bond Elect, Scotchbond Universal, All-Bond Universal, Clearfil Universal Bond and Futurabond U). Two bonding modes (etch-and-rinse and self-etch) were employed for each adhesive group. Bonded specimens were stored in deionized water for $24 \mathrm{hr}$ or underwent a 10,000-cycle thermocycling aging process prior to testing $(\mathrm{N}=10)$. Microtensile bond testing $(\mu \mathrm{TBS})$, transmission electron microscopy (TEM) of resin-dentin interfaces in non-thermocycled specimens and scanning electron microscopy (SEM) of tracer-infused water-rich zones within hybrid layers of thermocycled specimens were performed. Results: Both adhesive type and testing condition (with/without thermocycling) have significant influences on $\mu$ TBS. The use of each adhesive in either the etch-and-rinse or self-etch application mode did not result in significantly different $\mu$ TBS to dentin. Hybrid layers created by these adhesives in the etch-and-rinse bonding mode and self-etch bonding mode were $\sim 5 \mu \mathrm{m}$ and $\leq 0.5 \mu \mathrm{m}$ thick respectively. Tracer-infused regions could be identified within the resin-dentin interface from all the specimens prepared. Conclusion: The increase in versatility of universal adhesives is not accompanied by technological advances for overcoming the challenges associated with previous generations of adhesives. Therapeutic adhesives with bio-protective and bio-promoting effects are still lacking in commercialized adhesives.

Clinical significance: Universal adhesives represent manufacturers' attempt to introduce versatility in product design via adaptation of a single-bottle self-etch adhesive for other application modes without compromising its bonding effectiveness.

Keywords: dentin; bond strength; nanoleakage; universal adhesives 


\section{Introduction}

There is an ongoing trend among manufacturers to continue simplifying single-bottle bonding technology to satisfy clinicians' demand for adhesive procedures that are faster, less technique-sensitive and more user-friendly. ${ }^{1}$ The recently introduced clan of multi-mode universal adhesives is designed to bond to tooth structures via the etch-and-rinse technique or the self-etch technique using the same single bottle of adhesive solution, ${ }^{2}$ with claims by manufacturers that there is no compromise on bonding effectiveness when either bonding strategy is employed. Manufacturers of these adhesives suggest that they may also be used for elective etching of enamel margins. Examples of these universal adhesives include All-Bond Universal (Bisco, Inc., Schaumburg, IL, USA), Adhese Universal (Ivoclar-Vivadent, Schaan, Liechtenstein), Clearfil Universal Bond (Kuraray Noritake Dental Inc., Tokyo, Japan), Futurabond U (Voco GmbH, Cuxhaven, Germany), G-Premio Bond (GC Corp., Tokyo, Japan), Peak Universal Bond (Ultradent Products, Inc., South Jordan, UT, USA), Prime\&Bond Elect (Dentsply Caulk, Milford, DE, USA), and Scotchbond Universal (3M ESPE, St. Paul., MN, USA). Some of these universal adhesives also contain components that enable them to bond to silica-based glass ceramics or zirconia without the use of accessory priming agents.

Previously-marketed dental adhesive systems are designed to be used in either the etch-and-rinse or the self-etch mode, which may involve three, two, or a single application step. ${ }^{1}$ During the application of three-step or two-step etch-and-rinse adhesives, collagen fibrils demineralized by acid etching may collapse after air-drying of the etched dentin, leading to decreased bond strength. ${ }^{3}$ This necessitates the presence of a moist demineralized dentin surface to keep the collagen fibrils from collapsing. ${ }^{4}$ However, methods for controlling the moisture on the dentin surface and maintaining the original structure of collagen fibrils are highly subjective and technique-sensitive. ${ }^{5}$ Because of the concentration gradient exhibited by resin monomers in their course of infiltrating a thick bed of demineralized collagen matrix, resin-spare zones are created within the hybrid layer that are subsequently filled with water or dentinal fluid. ${ }^{6}$ These conditions may cause postoperative sensitivity, accelerate resin elution, or provide a water-rich niche for activation and functioning of endogenous collagenolytic 
enzymes present in the collagen matrix. ${ }^{7}$ Based on biomimetic remineralization studies, these water-rich, resin-sparse regions within the hybrid layers correspond to the sites of subsequent collagen degradation that undermine the longevity of resin-dentin bonds. ${ }^{8}$

Self-etch adhesives produce a hybridized complex comprising the residual smear layer and a thin, partially-demineralized dentin collagen matrix. ${ }^{9}$ Although self-etch adhesives do not require bonding to moist dentin and are less technique sensitive, they invariably contain water for ionization of the acidic resin monomers. ${ }^{10}$ Whereas water incorporated in self-etch adhesives may be removed by evaporation prior to polymerization of the adhesive monomers, the high concentration of ionic resin monomers in these adhesives causes osmotic imbibition of fluids derived from the underlying dentinal tubules and their ramifications. ${ }^{11}$ Heat produced during light-curing of the adhesives further generates convective movement of the entrapped water, causing it to be redistributed within the adhesive layer as minute water channels exhibiting fractal geometry (water trees). ${ }^{12}$ Although self-etch adhesives are designed to infiltrate where they demineralize, water-rich areas within the hybrid layers cannot be eliminated and are likewise manifested as nanoleakage when those hybrid layers are examined with a tracer. Because of the thinness of those hybrid layers, the area/volume ratio of nanoleakage to hybrid layer may even exceed that in hybrid layers created by etch-and-rinse adhesives. Collectively, nanoleakage and water-treeing are responsible for the increased permeability of resin-dentin interfaces created by self-etch adhesives. ${ }^{13}$ This increase in adhesive permeability is more severe for simplified one-step self-etch adhesives when compared to the two-step counterparts, with the latter incorporating a comparatively hydrophobic resin coating to cover the primed dentin surface. ${ }^{14}$

Because universal adhesives are marketed in fairly short order, ${ }^{15-18}$ relatively little information is available on their performance apart from those provided by the manufacturers, especially for the more recently introduced versions. As far as bonding to dentin is concerned, it is not known if equivalent bonding performance may be expected when these adhesives are used in either application mode, or whether this latest generation of adhesives has overcome some of the aforementioned critical barriers associated with contemporary dentin bonding. The present study examined the short-term in vitro performance of five universal adhesives bonded 
to human coronal dentin in the etch-and-rinse mode or the self-etch mode, by evaluating their microtensile bond strengths ( $\mu$ TBS) in the absence or presence of thermocycling. The null hypotheses tested were: 1) there is no difference among the five universal adhesives when they are used for bonding to dentin with either the etch-and-rinse mode or self-etch mode; 2) the adhesive application mode has no effect on the strength of the adhesive-dentin bonds of universal adhesives; and 3) the strength of the adhesive-dentin bonds of universal adhesives is not affected by thermocycling. In addition, the notion that the problems associated with dentin bonding in previous generation of adhesives have been resolved with the advent of universal adhesives was challenged by examining the ultrastructure of thermocycled specimens created by these adhesives in either bonding mode, for evidence of resin-sparse, water-rich regions within the resin-dentin interface.

\section{Materials and methods}

\section{Preparation of dentin specimens}

Two hundred non-carious human third molars were obtained based on a protocol approved by the Human Assurance Committee of Georgia Regents University. For each tooth, a flat dentin surface was prepared perpendicular to the longitudinal axis of the tooth using a low-speed diamond saw (Isomet, Buehler Ltd, USA) with water cooling. The enamel and superficial dentin were removed to expose the mid-coronal dentin. The exposed dentin surfaces were polished with wet 400 -grit silicon carbide paper to replace the diamond saw-created smear layer with a standardized smear layer. All surfaces were carefully verified using an optical microscope to ensure the absence of residual enamel or pulpal exposure.

\section{Bonding procedures}

The teeth were divided into five groups of 40 teeth each and randomly assigned to one of the five universal adhesives examined in the present study: Prime\&Bond Elect, Scotchbond Universal, All-Bond Universal, Clearfil Universal Bond and Futurabond U. The compositions of these adhesives are listed in Table I.

Each adhesive was applied to the mid-coronal dentin using the etch-and-rinse or the self-etch bonding mode. For the etch-and-rinse bonding mode, a 35\% phosphoric acid etchant 
(Select Hv Etch, Bisco, Inc.) was used for etching all teeth for $15 \mathrm{sec}$. This was followed by thorough rinsing of the etched dentin surface for $15 \mathrm{sec}$ to ensure complete removal of the etchant. The water present on the rinsed dentin surface was removed by gentle blowing with an air syringe or blot drying with a cotton pellet, according to the manufacturer's instructions of the respective adhesive. For the self-etch bonding mode, no etchant was used. The adhesives were meticulously applied according to the manufacturer's instructions (Table I). Two 2-mm-thick layers of a hybrid resin composite (TPH Spectra, Dentsply Caulk) were placed over the adhesive-bonded dentin surface of each tooth. Each resin composite was light cured for $40 \mathrm{sec}$ using a light-curing unit with an output density of $500 \mathrm{~mW} / \mathrm{cm}^{2}$.

Two testing conditions were employed for each bonding mode subgroup of the five universal adhesive ( $\mathrm{N}=10$ teeth): static and dynamic. The former was performed by storing the unsectioned teeth in deionized water at $37{ }^{\circ} \mathrm{C}$ for $24 \mathrm{hr}$. Dynamic testing was accomplished using thermocycling. Thermocycling was performed for 10,000 cycles at $5-55^{\circ} \mathrm{C}$ with a dwell time of $30 \mathrm{sec}$ in each water bath. The rationale for using the aforementioned number of cycles was based on the assumption that 10,000 thermocycles correspond approximately to one year of physiological aging in the oral cavity. ${ }^{19}$

\section{Microtensile bond testing ( $\mu$ TBS)}

Each bonded specimen was vertically sectioned into $0.9 \mathrm{~mm}$-thick resin-dentin slabs. Two central slabs from each tooth were sectioned into $0.9 \times 0.9-\mathrm{mm}^{2}$ sticks, each containing the adhesive joint in the center. The four longest sticks from those two slabs were selected, yielding 4 sticks per tooth. Therefore, each bonding mode subgroup of the five universal adhesive (with or without thermocycling) provided 4 × $20=80$ sticks for $\mu$ TBS testing.

Each stick was secured by cyanoacrylate glue to a testing jig and stressed to failure under tension using a universal tester (Vitrodyne V1000, LivecoInc, Burlington, VT, USA) at a cross-head speed of $1 \mathrm{~mm} / \mathrm{min}$. Statistical analysis was performed using tooth as the statistical unit; the mean $\mu$ TBS obtained from the 4 sticks of each tooth was used to represent the bond strength of that tooth. The data were analyzed using three-factor analysis of variance, to determine the effects of adhesive (i.e. the 5 universal adhesives), application mode (i.e. etch-and-rinse $v s$ self-etch) and testing condition (i.e. without $v s$ with thermocycling), and the 
interaction of these three factors on the bond strength results. The data sets were non-linearly transformed to satisfy the normality and equal variance assumptions, prior to using parametric statistical methods. Post-hoc multiple comparisons were performed using the Holm-Sidak method. For all analyses, statistical significance was set at $\alpha=0.01$.

After bond strength testing, the two ends of a fractured stick were carefully removed from the testing jig and examined under an optical microscope to determine the mode of failure. Failure modes were classified as adhesive failure (failure along the adhesive interface), mixed failure (failure within the adhesive joint with failure within the resin composite or dentin), or cohesive failure (failure within the resin composite or dentin).

\section{TEM of resin-dentin interfaces in non-thermocycled specimens}

Two additional slabs from each adhesive subgroup ( 2 bonding modes $\mathrm{x} 5$ adhesives) were processed for transmission electron microscopy (TEM). Each slab was completely demineralized in $0.1 \mathrm{M}$ formic acid/sodium formate $(\mathrm{pH} 2.5$ ). The end point of demineralization was determined by drop-wise addition of a $10 \%$ potassium oxalate solution to the demineralization medium, which formed a white calcium oxalate precipitate when calcium ions were present. Completely demineralized slabs containing the resin-dentin interface were fixed in Karnovsky's fixative $(2.5 \mathrm{wt} \%$ glutaraldehyde and 2\% paraformaldehyde in 0.1 mole/L cacodylate buffer; $\mathrm{pH}, 7.3$ ) for $8 \mathrm{hr}$, post-fixed in $1 \%$ osmium tetroxide for $1 \mathrm{hr}$, and. dehydrated in an ascending ethanol series (50-100\%), immersed in propylene oxide as a transition medium, and embedded in pure epoxy resin. Then, $90 \mathrm{~nm}$-thick sections were prepared using an ultramicrotome, stained with $2 \%$ aqueous uranyl acetate and Reynold's lead citrate, and examined using the JEM-1230 TEM (JEOL, Tokyo, Japan) operated at $110 \mathrm{keV}$.

\section{SEM of tracer-infused water-rich zones within hybrid layers of thermocycled specimens}

Four additional slabs from each adhesive subgroup ( 2 bonding modes $\mathrm{x} 5$ adhesives) were used for scanning electron microscopy (SEM). Each slab was wet-polished with 2000-grit silicon carbide paper and coated with nail varnish applied $1 \mathrm{~mm}$ from the bonded interface. The slab was immersed in $50 \mathrm{wt} \%$ ammoniacal silver nitrate solution ( $\mathrm{pH} 9.5)$ for $24 \mathrm{hr}$. The tracer-infused slab was subsequently immersed in a photodeveloping solution for 8 
hr under a fluorescent light to convert the tracer into metallic silver. Each slab was then gently wet-polished with 1200-grit silicon carbide papers to remove the surface layer of silver. Following air-drying, the slabs were coated with gold-palladium and examined using a field emission SEM (XL-30 FEG; Philips, Eindhoven, The Netherlands) at $30 \mathrm{kV}$. Imaging was performed using a combination of $70 \%$ backscattered electron mode and $30 \%$ secondary electron mode.

\section{Results}

Microtensile bond strength data of the five universal adhesives are presented in Table II. There was a statistically significant difference among the adhesives regarding their $\mu$ TBS derived from bonding to sound dentin $(\mathrm{P}<0.001)$. The difference between "application modes" was not significantly different $(\mathrm{P}=0.786)$. For the factor "testing condition", there was a statistically significant difference between specimens that had not undergone thermocycling and those that had been subjected to thermocycling $(\mathrm{P}<0.001)$.

For the interaction between these factors, the effect of different levels of "adhesive" was dependent on the level of "application mode"; there was a statistically significant interaction between "adhesive" and "application mode" $(\mathrm{P}<0.010)$. The effect of different levels of "adhesive" was independent of the level of "testing condition"; there was no statistically significant interaction between "adhesive" and "testing condition" $(\mathrm{P}=0.226)$. The effect of different levels of "application mode" was also independent of the level of "testing condition"; there was no statistically significant interaction between "application mode" and "testing condition" $(\mathrm{P}=0.440)$.

For the factor "adhesive", all pairwise comparisons were statistically significant except for the comparison between Prime\&Bond Elect and Scotchbond Universal $(\mathrm{P}=$ 0.704), between Prime\&Bond Elect and All-Bond Universal $(\mathrm{P}=0.037)$, between Scotchbond Universal and All-Bond Universal $(\mathrm{P}=0.076)$ and between Clearfil Universal Bond and Futurabond U (0.054). For the factor "testing condition", significant difference between the results of testing without thermocycling and testing with thermocycling was identified for Scotchbond Universal $(P=0.004)$, Clearfil Universal Bond $(\mathrm{P}=0.006)$ and Futurabond $\mathrm{U}(\mathrm{P}<0.001)$. By contrast, bonds created with Prime\&Bond 
Elect and All-Bond Universal were resistant to thermocycling $(\mathrm{P}>0.01)$. Pairwise comparisons of adhesives within the factor "application mode" and of adhesives within the factor "testing condition" are presented in Table III. Failure mode analysis for all groups (Figure 1) showed a few incidents of adhesive failure in all subgroups, irrespective of static or dynamic testing conditions. More than $50 \%$ of the specimens exhibited mixed failure, while the remaining showed cohesive failure.

Figure 2 shows the ultrastructure (left panels) and the appearance of tracer-infused water-rich zones (right panels) in representative specimens prepared from the use of the five universal adhesives in the etch-and-rinse bonding mode. All the hybrid layers were 5-6 $\mu \mathrm{m}$ thick, with collagen fibrils standing upright on the surface of those hybrid layers. When silica nanofillers were present in the adhesive, those nanofiller clusters were either bound to the demineralized collagen fibrils on the surface of the hybrid layer (as in Clearfil Universal Bond and Futurabond $\mathrm{U}$ ) or did not come into contact with the surface collagen fibrils (as in Scotchbond Universal). In either case, nanofillers could not be identified from the bulk of the hybrid layer (Figure 3). Tracer-infused regions could be identified within the resin-dentin interface from all the specimens prepared for SEM examination. They were manifested as a combination of fine tree-like structures that extended vertically from the surface of the hybrid layer into the adhesive, and as a fine dendritic pattern of silver deposits within the bulk of the hybrid layer. Hybrid layers created by Futurabond U consistently exhibited the most severe tracer infusion compared with those created by the other four adhesives.

Figure 4 shows the ultrastructure (left panels) and the appearance of tracer-infused water-rich zones (right panels) in representative specimens prepared from the use of the five universal adhesives in the self-etch bonding mode. Tracer-infused regions could be identified within the resin-dentin interface from all the specimens prepared for SEM examination. Although no statistical analysis was performed, it is evident that the area ratio of these silver-infused regions to the hybrid layer is considerably higher than what was observed in hybrid layers produced by the etch-and-rinse mode. It is not unusual to see hybrid layers that were completely impregnated with silver deposits across the entire length of the prepared specimens. Similar to the use of Futurabond $U$ in the etch-and-rinse mode, hybrid layers 
created by Futurabond $U$ in the self-etch mode consistently exhibited the most severe tracer infusion that extended as bulky water channels into the adhesive layer. In two specimens derived from FuturaBond U, hemispherical droplets that were filled entirely with silver deposits and continuous with completely silver-filled hybrid layers could be identified along the resin-dentin interface (not shown).

\section{Discussion}

When bonded to dentin, the five universal adhesives examined differed significantly in their $\mu \mathrm{TBS}$ irrespective of the application mode. Thus, the first null hypothesis that there is no difference among the five universal adhesives when they are used for bonding to dentin with either the etch-and-rinse mode or self-etch mode has to be rejected. Because the use of each adhesive in either the etch-and-rinse or self-etch application mode did not result in significantly different $\mu$ TBS to dentin, the second null hypothesis that the adhesive application mode has no effect on the strength of the adhesive-dentin bonds of universal adhesives cannot be rejected. The use of dynamic testing condition resulted in reduced $\mu$ TBS for three of the five universals. Thus, we have to reject the third null hypothesis that the strength of the adhesive-dentin bonds of universal adhesives is not affected by thermocycling.

Much progress had been made by the manufacturers of early generations of dentin adhesives by aligning their product development initiatives with the respective bonding strategies that emerged during those eras. As adhesive technologies became full-fledged, manufacturers began to simplify these systems into 2-step etch-and-rinse and all-in-one self-etch adhesives. In the strictest sense, these newer generations of dentin adhesives are products of convenience. The introduction of universal adhesives further inflates the all-in-one marketing model by embracing the versatility element in their multi-mode product design. A characteristic of many innovative products is product versatility. Versatility is usually accomplished using a multiple-component design; the versatile product being essentially a concept for marketing a package of compatible components. From a marketing perspective, universal adhesives are highly innovative products, offering the clinician the liberty of adapting a single-bottle self-etch adhesive for use in the etch-and-rinse mode or the selective enamel etching mode without compromising its bonding effectiveness. On further 
reflections, do these versatile innovations contain technological advances for overcoming challenges associated with previous generations of dentin adhesives? Admittedly, this issue cannot be fully addressed based on results derived from short-term in vitro studies alone. Nevertheless, it is appropriate to focus on a few specific issues that may be validated by our ongoing in vitro aging studies of resin-dentin interfaces created with these universal adhesives.

Blending of dental adhesives by highly skilled chemists is akin to the mixing of cocktails by professional bartenders. A lot of knowledge and expertise are required to blend functional acidic resin monomers, strength-providing cross-linking resin monomers, monofunctional resin monomer co-solvent, substrate-specific components, solvents, catalytic components and where necessary, rheology-modifying nanofillers, to create a miscible and stable adhesive cocktail that creates strong bonds with a variety of tooth substrates and dental restorative materials, is biocompatible with the pulpodentinal complex, and is practical to be applied within a clinically-realistic time frame. In this regard, universal adhesives are highly sophisticated cocktails which embrace virtually every element used in previous generations of dentin adhesives. In the past, self-etch adhesives are not recommended for use in the etch-and-rinse mode; several studies reported that some one-step self-etch adhesives produced inferior dentin bonding results when phosphoric acid was used prior to the application of those adhesives..$^{20,21}$ Depending on the $\mathrm{pH}$ and interaction depth with dentin, self-etch adhesives may be classified into ultra-mild ( $\mathrm{pH}>2.5,0.2-0.5 \mu \mathrm{m}$ interaction depth), mild $(\mathrm{pH} \approx 2 ; 0.5-1 \mu \mathrm{m}$ interaction depth), intermediate ( $\mathrm{pH}, 1-2 ; 1-2 \mu \mathrm{m}$ interaction depth), and strong ( $\mathrm{pH} \leq 1, \geq 5 \mu \mathrm{m}$ interaction depth, similar to etching with phosphoric acid). ${ }^{10}$ The more aggressive self-etch adhesives that contain substantial amounts of highly acidic resin monomers can induce continued etching along the base of hybrid layers after polymerization of those adhesives. ${ }^{22}$ Based on TEM observations, all the universal adhesives examined in the present study, with the exception of All-Bond Universal, may be classified as mild self-etch adhesives when they are used in the self-etch mode, creating hybrid layers that are approximately $0.5 \mu \mathrm{m}$ thick. All-Bond Universal may be classified as an ultra-mild self-etch adhesive because the hybrid layer is $0.2 \mu \mathrm{m}$ thick (Figure 4). By blending less acidic resin 
monomers in the appropriately reduced concentrations with other resin monomers, manufacturers appear to have solved the problem of bonding mode incompatibility and create multi-mode adhesive cocktails that bond equally well in the etch-and-rinse mode and the self-etch mode. The present observations that the use of universal adhesives in the etch-and-rinse mode has no adverse effect on the strength of adhesive-dentin bonds created by these adhesives are in support of the conclusion established by Wagner et al. ${ }^{15} \mathrm{In}$ that study, the bonding mode of universal adhesives (All-Bond Universal, Scotchbond Universal and Futurabond U) did not affect their $\mu$ TBS. ${ }^{15}$ Muñoz et al., however, reported otherwise, in that the application of All-Bond Universal and Peak Universal Adhesive in the self-etch mode to dentin resulted in significantly lower $\mu \mathrm{TBS}$ when compared to the application of those adhesives in the etch-and-rinse mode. ${ }^{18}$ According to these authors, only Scotchbond Universal was capable of producing similar $\mu$ TBS to dentin when the adhesive was applied in either bonding mode. These inter-laboratory differences are candid reflections of the adage that bond strength is not a material property. If bond strength indeed may be used as an indicator of bonding efficacy, there should be similar retention rates of class $\mathrm{V}$ resin composite restorations bonded by universal adhesives with either strategy. In their 18-month clinical study, Perdigão et al. showed that retention of class $\mathrm{V}$ resin composites bonded with Scotchbond Universal was not affected by the bonding strategy. ${ }^{23}$ Although one adhesive was examined in that clinical study, the results appear to validate those derived from in vitro bond strength testing of thermocycled specimens.

Although versatility in the universal adhesive design provides a freedom of choice for clinicians, the use of what are essentially one-step self-etch adhesives for bonding in the etch-and-rinse mode defeats the purpose of using functional resin monomers that have the potential to bond chemically to apatite. Moreover, the bonding mechanism of etching and infiltrating simultaneously is replaced by one which relies on diffusion to achieve micromechanical retention, ${ }^{3,10,24,25}$ with the likelihood of incomplete infiltration of resin monomers within a thick, completely demineralized collagen matrix. According to the adhesion-decalcification (A-D) concept proposed for self-etching adhesives, ${ }^{26,27}$ aggressive demineralization of hard tissues by strong acids will result in dissolution of apatite crystallites. 
This abolishes the potential opportunity to establish a chemical bond between functional adhesive resin monomers and apatite crystallites, as well as the potential for creating nano-layers of calcium precipitates with phosphate resin monomers with long spacer groups. ${ }^{28-31}$ This is particularly so for the three universal adhesives containing the acidic resin monomer 10-MDP (10-methacryloyloxydecyl dihydrogen phosphate), which has been coined by the proponents of the A-D concept as the quintessential functional resin monomer for chemical bonding to apatite. ${ }^{30}$ Although the deposition of water-insoluble 10-MDP-calcium salts has minimal effect on the immediate bond strength of self-etched dentin, proponents of the A-D concept claim that these salts contribute to bond durability by protecting the hybrid layer from hydrolytic degradation. ${ }^{10}$ Nevertheless, the validity of this claim requires substantiation. Despite meticulous demonstration of the chemical interaction of 10-MDP with hydroxyapatite, the potential of 10-MDP in improving bond stability is debatable after it is blended and diluted with other resin monomers to produce dentin adhesives. Scotchbond Universal includes another functional monomer, polyalkenoic acid copolymer (VitrebondTM). The three 10-MDP containing universal adhesives also contain hydroxyethyl methacrylate (HEMA) as a monofunctional resin monomer co-solvent. Both HEMA and the polyalkenoic acid copolymer reportedly compete with 10-MDP for the calcium coordination sites on the surface of apatite crystallites, resulting in markedly reduced nano-layering of 10-MDP-calcium salts within the resin-dentin interface. ${ }^{32}$ In the present work, Clearfil Universal Bond (with 10-MDP) did not appear to exhibit better performance than the non-MDP containing Prime\&Bond Elect after thermocycling. Although Muñoz et al. that universal adhesives containing 10-MDP exhibited higher and more stable $\mu$ TBS with reduced interfacial nanoleakage after 6 months of water storage, ${ }^{33}$ it is inexplicable why bonds created by Scotchbond Universal in the etch-and-rinse mode were relatively stable, while bonds created by All-Bond Universal using the same etching mode exhibited severe degradation. Although both universal adhesives contain 10-MDP, there should be minimal chemical interaction between 10-MDP and apatite crystallites since the latter were completely removed from the demineralized collagen matrix after phosphoric acid-etching and water-rinsing. In a previous study on Clearfil SE Bond (Kuraray Noritake Dental Inc.), a 
MDP-containing two-step self-etch adhesive, degradation still occurred after 12 months of in vivo or in vitro aging, ${ }^{34}$ despite demonstration of nano-layering within the resin-dentin interface. $^{31}$ This may be attributed to hydrolytic degradation of the ester functionality in 10-MDP and other methacrylate resin monomers on the one hand, ${ }^{35,36}$ and enzymatic degradation of apatite-sparse collagen by endogenous collagenolytic enzymes on the other hand. ${ }^{37}$ The results from the study by Donmez et al. ${ }^{34}$ suggest that resin-dentin interfaces created by contemporary universal adhesives containing 10-MDP may not be as immune to degradation as the manufacturers would like to see.

Because water is required for hydrolytic degradation of polymeric resins ${ }^{38,39}$ and enzymatic degradation of collagen fibrils, ${ }^{40,41}$ it is logical to use a water-based tracer solution to probe regions that are permeable to water in resin-dentin interfaces that have been subjected to thermocycling. Based on the present nanoleakage results, the potential of universal adhesives to resist water aging is unlikely to be different from previous generation of dentin adhesives. Tracer-infused regions could be identified from resin-dentin interfaces created by the five universal adhesives in the etch-and-rinse mode. For the self-etch mode, because of the thinness of the hybrid layers, the area ratio of nanoleakage to the hybrid layer even exceeded the ratio identified from hybrid layers created by etch-and-rinse adhesives. This observation suggests that resin-dentin interfaces created by all five adhesives in the self-etch mode contain incompletely removed water. In the present study, no statistical analysis was performed to compare the nanoleakage present in the resin-dentin interfaces created by different adhesives. To the authors, quantification is not the issue because nanoleakage is simply a phenomenological expression of the inability of contemporary adhesive techniques to replace the free water removal mechanism in biomineralization. As long as the phenomenon is expressed, the ultimate outcome remains the same irrespective of its severity. Prime\&Bond Elect contains acetone as a solvent, while the others contain ethanol. Water is comparatively easy to remove with the use of an acetone-based adhesive because its azeotrope contains more water and has a higher vapor pressure. ${ }^{42}$ Conversely, the solvent in ethanol-based adhesives has an increased ability to form hydrogen bonds and it is not easy to eliminate the last traces of water from the adhesive. ${ }^{43}$ In the present work, the manufacturers' 
solvent evaporation time was followed. According to the recent study of Luque-Martinez et

al. ${ }^{44}$ nanoleakage expression was markedly reduced when the solvent evaporation times were increased to $25 \mathrm{sec}$. The authors concluded that entrapment of residual water in the resin-dentin interface compromises the performance of universal adhesives, and water elimination may be improved with extended solvent evaporation times. In addition, conversion of these adhesives from one-step self-etch application to two-step self-etch application by the addition of a relatively hydrophobic resin coating did not appear to contribute much in reducing the water entrapped within the resin-dentin interfaces created by some of these universal adhesives. ${ }^{45}$

Although the thermocycling regime employed in present study has been reported to approximate one year of physiological aging in the oral cavity, it does not replace long-term aging evaluation. Thermocycling is a commonly used artificial aging method because it creates cyclic expansion and contraction stresses along the resin-dentin interface. Immersion in hot water may also result in extraction and elution of incompletely polymerized adhesive resin components as well as expediting the decomposition of unprotected collagen fibrils. ${ }^{46}$ However, there is no evidence indicating that thermocycling is sufficient to activate matrix-bound matrix metalloproteinases and cysteine cathepsins within the demineralized collagen matrix. Thus, long-term water aging study is still required to evaluate the resistance of resin-dentin interfaces created by contemporary universal adhesives to water sorption-induced degradation.

\section{Conclusion}

Taken together, the preliminary data generated from immediate bonding and after thermocycling of dentin specimens bonded with the universal adhesives studied appear to suggest that these adhesives should perform no differently from previous generations of etch-and-rinse adhesives or self-etch adhesives. While such a premise has to be validated by ongoing long-term aging studies and future clinical studies, it is pertinent to note that the increase in versatility in these commercialized products is not accompanied by technological advances for overcoming the challenges associated with previous generations of dentin adhesives. These advances include incentives for eliminating free water from resin-dentin 
interfaces, for inhibiting collagen degradation, and for inhibiting attachment of dental plaque biofilms that are responsible for initiating secondary caries. It appears that a plateau has been reached in dentin adhesive development, at least on the part contributed by manufacturers, and that there is a limit to what may be creatively accomplished using the expertise of blending and mixing existing adhesive components. To the authors, the introduction of the current generation of universal adhesives is like placing old wines in new bottles - there is no breaking of new ground. It is worth revisiting what our forefathers have accomplished during the first fifty years of development in adhesive dentistry and to further reflect upon the exciting research performed by scientists over the past decade in moving adhesive dentistry into a new era which encompasses new bioactive concepts that are sprouting in the field of tissue engineering. In marketing terms, putting old wines into new bottles is no doubt a successful investment achieved via inclusion of the element of versatility in product design. As we celebrate the $60^{\text {th }}$ anniversary of adhesive dentistry in 2015, there must be manufacturers with clairvoyant visions who are willing to lead the sublimation of dentin adhesives from their current passive role as a component of an adhesive joint, to therapeutic products with more noble objectives. ${ }^{47}$ In the words of Warrant Bennett, the pioneer of the contemporary field of leadership studies: "Leadership is the capacity to translate vision into reality". This has been seen in the past with various facets of adhesive dentistry, from the advent of the concept of minimally invasive cavity preparation, to the adoption of wet water bonding in the etch-and-rinse technique, to the development of simplified all-in-one adhesives, to the appearance of self-etch resin cements, to the incorporation of 10-MDP for multi-mode bonding in dentin adhesives, just to name a few. After all, in the business version of "The Hunger Games", 48 there is no lone player; each game player is anxiously waiting for a peer to take the initiative; once a leader emerges, others will follow. 


\section{References}

1. De Munck J, Van Landuyt K, Peumans M, Poitevin A, Lambrechts P, Braem M, et al. A critical review of the durability of adhesion to tooth tissue: methods and results. Journal of Dental Research 2005; 84: 118-32.

2. Hanabusa M, Mine A, Kuboki T, Momoi Y, Van Ende A, Van Meerbeek B, et al. Bonding effectiveness of a new 'multi-mode' adhesive to enamel and dentine. Journal of Dentisty 2012; 40: $475-84$.

3. Pashley DH, Tay FR, Breschi L, Tjäderhane L, Carvalho RM, Carrilho M, et al. State of the art etch-and-rinse adhesives. Dental Materials 2011; 27: 1-16.

4. Pashley DH, Tay FR, Carvalho RM, Rueggeberg FA, Agee KA, Carrilho M, et al. From dry bonding to water-wet bonding to ethanol-wet bonding A review of the interactions between dentin matrix and solvated resins using a macromodel of the hybrid layer. American Journal of Dentistry 2007; 20: 7-20.

5. Tay FR, Pashley DH. Have dentin adhesives become too hydrophilic? Journal of Canadian Dental Association 2003; 69: 726-31.

6. Malacarne J, Carvalho RM, de Goes MF, Svizero N, Pashley DH, Tay FR, et al. Water sorption/solubility of dental adhesive resins. Dental Materials 2006; 22: 973-80.

7. Pashley DH, Tay FR, Yiu C, Hashimoto M, Breschi L, Carvalho RM, et al. Collagen degradation by host-derived enzymes during aging. Journal of Dental Research 2004; 83: 216-21.

8. Brackett MG, Li N, Brackett WW, Sword RJ, Qi YP, Niu LN, et al. The critical barrier to progress in dentine bonding with the etch-and-rinse technique. Journal of Dentistry 2011; 39: $238-48$.

9. Van Landuyt KL, De Munck J, Mine A, Cardoso MV, Peumans M, Van Meerbeek B. Filler debonding \& subhybrid-layer failures in self-etch adhesives. Journal of Dental Research 2010; 89: 1045-50.

10. Van Meerbeek B, Yoshihara K, Yoshida Y, Mine A, De Munck J, Van Landuyt KL. State of the art of self-etch adhesives. Dental Materials 2011; 27: 17-28.

11. Sauro S, Pashley DH, Montanari M, Chersoni S, Carvalho RM, Toledano M, et al. Effect 
of simulated pulpal pressure on dentin permeability and adhesion of self-etch adhesives. Dental Materials 2007; 23: 705-13.

12. Tay FR, Pashley DH, Suh BI, Hiraishi N, Yiu CK. Water treeing in simplified dentin adhesives--déjà vu? Operative Dentistry 2005; 30: 561-79.

13. Chersoni S, Suppa P, Grandini S, Goracci C, Monticelli F, Yiu C, et al. In vivo and in vitro permeability of one-step self-etch adhesives. Journal of Dental Research 2004; 83: 459-64.

14. King NM, Tay FR, Pashley DH, Hashimoto M, Ito S, Brackett WW, et al. Conversion of one-step to two-step self-etch adhesives for improved efficacy and extended application. American Journal of Dentistry 2005; 18: 126-34.

15. Wagner A, Wendler M, Petschelt A, Belli R, Lohbauer U. Bonding performance of universal adhesives in different etching modes. Journal of Dentistry 2014; 42: 800-7.

16. Kearns JO, Barry JG, Fleming GJ. Cuspal deflection and cervical microleakage scores to determine the adhesive potential of universal bonding systems. Journal of Dentistry 2014; 42: 970-6.

17. Luque-Martinez IV, Perdigão J, Muñoz MA, Sezinando A, Reis A, Loguercio AD. Effects of solvent evaporation time on immediate adhesive properties of universal adhesives to dentin. Dental Material 2014; 30: 1126-35.

18. Muñoz MA, Luque I, Hass V, Reis A, Loguercio AD, Bombarda NH. Immediate bonding properties of universal adhesives to dentine. Journal of Dentistry 2013; 41: 404-11.

19. Gale MS, Darvell BW. Thermal cycling procedures for laboratory testing of dental restorations. Journal of Dentistry 1999; 27: 89-99.

20. Torii Y, Itou K, Nishitani Y, Ishikawa K, Suzuki K. Effect of phosphoric acid etching prior to self-etching primer application on adhesion of resin composite to enamel and dentin. American Journal of Dentistry 2002; 15: 305-8.

21. Van Landuyt KL, Peumans M, De Munck J, Lambrechts P, Van Meerbeek B. Extension of a one-step self-etch adhesive into a multi-step adhesive. Dental Material 2006; 22: 533-44. 22. Wang Y, Spencer P. Continuing etching of an all-in-one adhesive in wet dentin tubules. Journal of Dental Research 2005; 84: 350-4.

23. Perdigão J, Kose C, Mena-Serrano AP, De Paula EA, Tay LY, Reis A, et al. A new 
universal simplified adhesive: 18-month clinical evaluation. Operative Dentistry 2014; 39: $113-27$.

24. Yoshida Y, Nagakane K, Fukuda R, Nakayama Y, Okazaki M. Comparative study on adhesive performance of functional monomers. Journal of Dental Research 2004; 83: 454-8.

25. Van Landuyt KL, Yoshida Y, Hirata I, Snauwaert J, De Munck J, Okazaki M, et al. Influence of the chemical structure of functional monomers on their adhesive performance. Journal of Dental Research 2008; 87: 757-61.

26. Yoshida Y, Van Meerbeek B, Nakayama Y, Yoshioka M, Snauwaert J, Abe Y, et al. Adhesion to and decalcification of hydroxyapatite by carboxylic acids. Journal of Dental Research 2001; 80:1565-9.

27. Yoshioka M, Yoshida Y, Inoue S, Lambrechts $\mathrm{P}$, Vanherle G, Nomura $\mathrm{Y}$, et al. Adhesion/decalcification mechanisms of acid interactions with human hard tissues. Journal of Biomedical Materials Research 2002; 59: 56-62.

28. Yoshida Y, Van Meerbeek B, Nakayama Y, Snauwaert J, Hallemans L, Lambrechts P, et al. Evidence of chemical bonding at biomaterial-hard tissue interfaces. Journal of Dental Research 2000; 79: 709-14.

29. Yoshihara K, Yoshida Y, Nagaoka N, Fukegawa D, Hayakawa S, Mine A, et al. Nano-controlled molecular interaction at adhesive interfaces for hard tissue reconstruction. Acta Biomaterialia 2010; 6: 3573-82.

30. Yoshihara K, Yoshida Y, Hayakawa S, Nagaoka N, Irie M, Ogawa T, Van Landuyt KL, Osaka A, Suzuki K, Minagi S, Van Meerbeek B. Nanolayering of phosphoric acid ester monomer on enamel and dentin. Acta Biomaterialia 2011; 7: 3187-95.

31. Yoshida Y, Yoshihara K, Nagaoka N, Hayakawa S, Torii Y, Ogawa $\mathrm{T}$, et al. Self-assembled nano-layering at the adhesive interface. Journal of Dental Research 2012; 91:376-81.

32. Yoshida Y, Yoshihara K, Hayakawa S, Nagaoka N, Okihara T, Matsumoto T, et al. HEMA inhibits interfacial nano-layering of the functional monomer MDP. Journal of Dental Research 2012; 91:1060-5. 
33. Muñoz M, Luque-Martinez I, Malaquias P, Hass V, Reis A, Campanha N, et al. In vitro longevity of bonding properties of universal adhesives to dentin. Operative Dentistry 2014; [Epub ahead of print].

34. Donmez N, Belli S, Pashley DH, Tay FR. Ultrastructural correlates of in vivo/in vitro bond degradation in self-etch adhesives. Journal of Dental Research 2005; 84: 355-9.

35. Salz U, Zimmermann J, Zeuner F, Moszner N. Hydrolytic stability of self-etching adhesive systems. Journal of Adhesive Dentistry 2005; 7: 107-16.

36. Spencer P, Ye Q, Park J, Topp EM, Misra A, Marangos O, et al. Adhesive/Dentin interface: the weak link in the composite restoration. Annals of Biomedical Engineering 2010; 38: 1989-2003.

37. Tjäderhane L. Dentin bonding: Can we make it last? Operative Dentistry 2015; 40: 4-18.

38. Carrilho MR, Carvalho RM, Tay FR, Yiu C, Pashley DH. Durability of resin-dentin bonds related to water and oil storage. American Journal of Dentistry 2005; 18: 315-9.

39. Spencer P, Ye A, Park J, Misra A, Bohaty BS, Singh V. Durable bonds at the adhesive/dentin interface: an impossible mission or simply a moving target? Brazilian Dental Science 2012; 15: 4-18.

40. Kim YK, Mai S, Mazzoni A, Liu Y, Tezvergil-Mutluay A, Takahashi K, et al. Biomimetic remineralization as a progressive dehydration mechanism of collagen matrices--implications in the aging of resin-dentin bonds. Acta Biomaterialia 2010; 6: 3729-39.

41. Liu Y, Tjäderhane L, Breschi L, Mazzoni A, Li N, Mao J, et al. Limitations in bonding to dentin and experimental strategies to prevent bond degradation. Journal of Dental Research 2011; 90: 953-68.

42. Pashley EL, Zhang Y, Lockwood PE, Rueggeberg FA, Pashley DH. Effects of HEMA on water evaporation from water-HEMA mixtures. Dental Materials 1998; 14: 6-10.

43. Cadenaro M, Breschi L, Rueggeberg FA, Suchko M, Grodin E, Agee KA, et al. Effects of residual ethanol on the rate and degree of conversion of five experimental resins. Dental Materials 2009; 25: 621-8.

44. Luque-Martinez IV, Perdigão J, Muñoz MA, Sezinando A, Reis A, Loguercio AD. Effects of solvent evaporation time on immediate adhesive properties of universal adhesives to dentin. Dental Materials 2014; 30: 1126-35. 
45. Muñoz MA, Sezinando A, Luque-Martinez I, Szesz AL, Reis A, Loguercio AD, et al. Influence of a hydrophobic resin coating on the bonding efficacy of three universal adhesives. Journal of Dentistry 2014; 42: 595-602.

46. Morresi AL, D'Amario M, Capogreco M, Gatto R, Marzo G, D'Arcangelo C, et al. Thermal cycling for restorative materials: does a standardized protocol exist in laboratory testing? A literature review. Journal of the Mechanical Behavior of Biomedical Materials 2014; 29: 295-308.

47. Imazato S, Ma S, Chen J-H, Xu HHK. Therapeutic polymers for dental adhesives: Loading resins with bio-active components. Dental Materials 2014; 30: 97-104.

48. Collins S. The Hunger Games. New York: Scholastic, Scholastic Press, 2008. 


\section{Figure Legends}

Figure 1 Failure modes of the five universal adhesives bonded to dentin in the etch-and-rinse mode and the self-etch mode, with and without thermocycling.

Figure 2 Universal adhesives bonded to dentin using the etch-and-rinse mode. A. Prime\&Bond Elect; B. Scotchbond Universal; C. All-Bond Universal; D. Clearfil Universal Bond; E. Futurabond U. Left column: Transmission electron microscopy images (left panel) of resin-dentin interfaces prepared from stained demineralized sections. Abbreviations: A: adhesive; D: dentin; between open arrowheads: hybrid layer. $\mathrm{Bar}=2 \mu \mathrm{m}$. Right column: Representative scanning electron microscopy of silver-infused water-rich regions (arrows) along the resin-dentin interface. Bar $=5 \mu \mathrm{m}$.

Figure 3 High magnification transmission electron microscopy images of stained, demineralized sections showing the relationship between nanosilica clusters (arrows) present in filler-containing universal adhesives and the completely demineralized collagen fibrils on the surface of the hybrid layer $(\mathrm{H})$. Bar $=500 \mathrm{~nm}$. A. Scotchbond Universal. Nanofillers appeared to be separated from the dentin surface by a filler-sparse region (probably the water tree zone shown in right image of Fig. 2B). B. Futurabond U. Nanofillers adhered to the surface collagen fibrils only (arrowhead) and did not penetrate the bulk of the hybrid layer.

Figure 4 Universal adhesives bonded to dentin using the self-etch mode. A. Prime\&Bond Elect; B. Scotchbond Universal; C. All-Bond Universal; D. Clearfil Universal Bond; E. Futurabond U. Left column: Transmission electron microscopy images (left panel) of resin-dentin interfaces prepared from stained demineralized sections. Abbreviations: A: adhesive; D: dentin; between open arrowheads: hybrid layer. Bar $=500 \mathrm{~nm}$. In Figure 4E, smear layer remnants (pointer) were incorporated into the hybrid layer of Futurabond U. Right column: Representative scanning electron microscopy of silver-infused water-rich regions (arrows) along the resin-dentin interface. Bar $=10 \mu \mathrm{m}$. In Figure 4E, a gap (asterisk) was present between the Futurabond $\mathrm{U}$ adhesive and the surface of the hybrid layer. As this gap did not contain silver, it was probably an artifactual gap created by dehydration during specimen preparation. 
Table I Adhesive system, composition and application mode of the adhesive systems used according to the manufacturer's instructions

\begin{tabular}{|c|c|c|c|c|}
\hline Adhesive & $\mathrm{pH}$ & Composition & Self-etch strategy & Etch-and-rinse strategy \\
\hline $\begin{array}{l}\text { Prime\&Bond } \\
\text { Elect } \\
\text { (Dentsply Caulk, } \\
\text { USA) }\end{array}$ & 2.5 & $\begin{array}{l}\text { Mono-, di- and } \\
\text { trimethacrylate } \\
\text { resins, PENTA, } \\
\text { diketone, stabilizers } \\
\text { organic phosphine } \\
\text { oxide, cetylamine } \\
\text { hydrofluoride, } \\
\text { acetone, water, } \\
\text { self-cure activator }\end{array}$ & $\begin{array}{l}\text { 1. Apply generous } \\
\text { amounts of adhesive to } \\
\text { thoroughly wet all the } \\
\text { tooth surfaces. } \\
\text { 2. Agitate the applied } \\
\text { adhesive for } 20 \text { sec. } \\
\text { Re-wetting of the } \\
\text { microbrush may be } \\
\text { required in order to coat } \\
\text { the preparation for the } \\
\text { entire } 20 \text { sec period. } \\
\text { 3. Remove excess } \\
\text { solvent by gentle drying } \\
\text { with clean, dry air from } \\
\text { a dental syringe for at } \\
\text { least } 5 \text { sec. } \\
\text { 4. Light cure for } 10 \text { sec. }\end{array}$ & $\begin{array}{l}\text { 1. Apply etchant for } 15 \\
\text { sec. } \\
\text { 2. Rinse thoroughly } \\
\text { for at least } 15 \text { sec. } \\
\text { 3. Remove rinsing water } \\
\text { completely by blowing } \\
\text { gently with an air syringe } \\
\text { or by blot drying with a } \\
\text { cotton pellet. } \\
\text { 4. Apply adhesive as for } \\
\text { the self-etch mode }\end{array}$ \\
\hline $\begin{array}{l}\text { Scotchbond } \\
\text { Universal } \\
(3 \mathrm{M} \text { ESPE, USA) }\end{array}$ & 2.7 & $\begin{array}{l}\text { 10-MDP, HEMA, } \\
\text { silane, } \\
\text { dimethacrylate } \\
\text { resins, Vitrebond } \\
\text { copolymer, filler, } \\
\text { ethanol, water, } \\
\text { initiators }\end{array}$ & $\begin{array}{l}\text { 1. Apply the adhesive or } \\
\text { adhesive mixture to the } \\
\text { prepared tooth and rub it } \\
\text { in for } 20 \mathrm{sec} \text {. } \\
\text { 2. Gently air-dry the } \\
\text { adhesive for } \\
\text { approximately } 5 \mathrm{sec} \text { for } \\
\text { the solvent to evaporate. } \\
\text { 3. Light cure for } 10 \mathrm{sec} \text {. }\end{array}$ & $\begin{array}{l}\text { 1. Apply etchant for } 15 \\
\text { sec. } \\
\text { 2. Rinse thoroughly with } \\
\text { water and dry with } \\
\text { water-free and oil-free air } \\
\text { or with cotton pellets; do } \\
\text { not overdry. } \\
\text { 3. Apply adhesive as for } \\
\text { the self-etch mode }\end{array}$ \\
\hline $\begin{array}{l}\text { All-Bond } \\
\text { Universal } \\
\text { (Bisco Inc., } \\
\text { USA) }\end{array}$ & 3.2 & $\begin{array}{l}\text { Bis-GMA, 10-MDP, } \\
\text { HEMA, ethanol, } \\
\text { initiators, water }\end{array}$ & $\begin{array}{l}\text { 1. Apply two separate } \\
\text { coats of adhesive with } \\
\text { agitation for } 10-15 \mathrm{sec} \\
\text { per coat. } \\
2 \text {. Evaporate solvent by } \\
\text { thorough air-drying } \\
\text { using an air syringe for } \\
\text { at least } 10 \text { sec. There } \\
\text { should be no visible } \\
\text { movement of the } \\
\text { adhesive. }\end{array}$ & $\begin{array}{l}\text { 1. Etch for } 15 \text { sec. } \\
2 \text {. Rinse thoroughly. } \\
\text { 3. Remove excess water } \\
\text { by blotting the surface } \\
\text { with an absorbent pellet } \\
\text { or high volume } \\
\text { evacuation for } 1-2 \mathrm{sec} \text {, } \\
\text { leaving the preparation } \\
\text { visibly moist } \\
\text { 4. Apply adhesive as for } \\
\text { the self-etch mode. }\end{array}$ \\
\hline
\end{tabular}




\begin{tabular}{|c|c|c|c|c|}
\hline Table I (Contd.) & & & $\begin{array}{l}\text { 3. The surface should } \\
\text { have a uniform glossy } \\
\text { appearance. If not, } \\
\text { repeat steps } 1 \text { and } 2 \text {. } \\
\text { 4. Light cure for } 10 \mathrm{sec} \text {. }\end{array}$ & \\
\hline $\begin{array}{l}\text { Clearfil Universal } \\
\text { Bond } \\
\text { (Kuraray } \\
\text { Noritake Dental } \\
\text { Inc., Japan) }\end{array}$ & 2.3 & $\begin{array}{l}\text { Bis-GMA, HEMA, } \\
\text { ethanol, 10-MDP, } \\
\text { hydrophilic aliphatic } \\
\text { dimethacrylate, } \\
\text { colloidal silica, } \\
\text { dl-camphorquinone, } \\
\text { silane coupling } \\
\text { agent, accelerators, } \\
\text { initiators, water }\end{array}$ & $\begin{array}{l}\text { 1. Apply Clearfil } \\
\text { Universal Bond to the } \\
\text { entire cavity wall with } \\
\text { the applicator brush and } \\
\text { rub it in for } 10 \text { sec. } \\
\text { 2. Dry the cavity wall } \\
\text { sufficiently by blowing } \\
\text { mild air for more than } 5 \\
\text { sec until the adhesive } \\
\text { shows no movement. } \\
\text { Use a vacuum aspirator } \\
\text { to prevent the adhesive } \\
\text { from scattering. } \\
\text { 3. Light cure for } 10 \mathrm{sec} \text {. }\end{array}$ & $\begin{array}{l}\text { 1. Apply a phosphoric } \\
\text { acid etching gel, leave it } \\
\text { in place for } 15 \mathrm{sec} \text {, then } \\
\text { rinse and dry. } \\
\text { 2. Apply adhesive as for } \\
\text { the self-etch mode. }\end{array}$ \\
\hline $\begin{array}{l}\text { Futurabond U } \\
\text { (Voco GmbH, } \\
\text { Germany) }\end{array}$ & 2.3 & $\begin{array}{l}\text { HEMA, Bis-GMA, } \\
\text { HEDMA, acidic } \\
\text { adhesive monomer, } \\
\text { urethane } \\
\text { dimethacrylate, } \\
\text { catalyst, silica } \\
\text { nanoparticles, } \\
\text { ethanol }\end{array}$ & $\begin{array}{l}\text { 1. Activate single dose } \\
\text { adhesive package. } \\
\text { 2. Apply adhesive to the } \\
\text { cavity surface using the } \\
\text { Voco Single Tim brush } \\
\text { and rub adhesive in for } \\
20 \text { sec. } \\
\text { 3. Dry off adhesive with } \\
\text { dry, oil-free air for at } \\
\text { least } 5 \text { sec to remove } \\
\text { any solvents. } \\
\text { 4. Light cure for } 10 \mathrm{sec} \text {. }\end{array}$ & $\begin{array}{l}\text { 1. Etch the surfaces to be } \\
\text { etched using a dental } \\
\text { acid-etch agent based on } \\
\text { phosphoric acid for } 15 \mathrm{sec} \\
\text { 2. Aspirate the acid-etch } \\
\text { agent, rinse with water for } \\
\text { approximate } 15 \text { sec. } \\
\text { 3. Dry off excess } \\
\text { moisture with a gentle } \\
\text { stream of air to produce a } \\
\text { silky matte surface } \\
\text { appearance. Do not } \\
\text { overdry the dentin. } \\
\text { 4. Apply adhesive as for } \\
\text { the self-etch mode. }\end{array}$ \\
\hline
\end{tabular}

Abbreviations - 10-MDP: 10-methacryloyloxydecyl dihydrogen phosphate; Bis-GMA: bisphenol A glycidyl methacrylate; HEDMA: 1,6-hexanediol dimethacrylate; HEMA: 2-hydroxyethyl methacrylate; PENTA: dipentaerythritol penta acrylate monophosphate 
Table II. Microtensile bond strength of the five universal adhesives bonded to dentin using two application modes, with and without thermocycling

\begin{tabular}{lcccc}
\hline \multirow{2}{*}{\multicolumn{1}{c}{ Adhesive }} & \multicolumn{2}{c}{ Etch-and-rinse mode (MPa) } & \multicolumn{2}{c}{ Self-etch mode (MPa) } \\
\cline { 2 - 5 } & $\begin{array}{c}\text { No } \\
\text { thermocycling }\end{array}$ & $\begin{array}{c}\text { After } \\
\text { thermocycling }\end{array}$ & $\begin{array}{c}\text { No } \\
\text { thermocycling }\end{array}$ & $\begin{array}{c}\text { After } \\
\text { thermocycling }\end{array}$ \\
\hline \hline Prime\&Bond Elect & $57.8 \pm 9.1$ & $51.5 \pm 9.7$ & $56.3 \pm 10.2$ & $54.1 \pm 10.6$ \\
Scotchbond Universal & $55.7 \pm 10.7$ & $47.1 \pm 8.8$ & $59.9 \pm 11.8$ & $55.8 \pm 11.9$ \\
All-Bond Universal & $54.6 \pm 8.3$ & $51.1 \pm 7.8$ & $50.1 \pm 6.8$ & $47.8 \pm 9.5$ \\
Clearfil Universal Bond & $49.1 \pm 4.2$ & $42.5 \pm 4.1$ & $48.0 \pm 7.4$ & $44.1 \pm 9.6$ \\
Futurabond U & $46.5 \pm 7.2$ & $40.0 \pm 6.2$ & $48.2 \pm 9.7$ & $38.4 \pm 10.1$ \\
\hline \hline
\end{tabular}

Values are means \pm standard deviations in megaPascals (MPa; $\mathrm{N}=10$ teeth) 
Table III. Pairwise comparison of adhesive groups within factors

\begin{tabular}{|c|c|c|c|c|}
\hline \multirow{2}{*}{ Pairwise comparison } & \multicolumn{2}{|c|}{$\begin{array}{c}\text { Adhesive within } \\
\text { "application mode" } \\
(\text { P value })^{\dagger}\end{array}$} & \multicolumn{2}{|c|}{$\begin{array}{c}\text { Adhesive within } \\
\text { "tesing condition" } \\
\text { (P value) })^{\dagger}\end{array}$} \\
\hline & $\begin{array}{l}\text { Etch-and- } \\
\text { rinse } \\
\text { mode }\end{array}$ & $\begin{array}{c}\text { Self-etch } \\
\text { mode }\end{array}$ & $\begin{array}{c}\text { Without } \\
\text { thermocycli } \\
\text { ng }\end{array}$ & $\begin{array}{c}\text { After } \\
\text { therocyclin } \\
\mathrm{g}\end{array}$ \\
\hline Prime\&Bond Elect vs Futurabond U & $<0.001 *$ & $<0.001 *$ & $<0.001 *$ & $<0.001 *$ \\
\hline Scotchbond Universal vs Futurabond U & $0.001 *$ & $<0.001 *$ & $<0.001 *$ & $<0.001 *$ \\
\hline All-Bond Universal vs Futurabond U & $<0.001 *$ & $0.006 *$ & 0.059 & $<0.001 *$ \\
\hline Prime\&Bond Elect $v s$ Clearfil Universal Bond & $0.001 *$ & $<0.001 *$ & $0.001 *$ & $<0.001 *$ \\
\hline Scotchbond Universal vs Clearfil Universal Bond & 0.104 & $<0.001 *$ & $<0.001 *$ & $0.001 *$ \\
\hline All-Bond Universal vs Clearfil Universal Bond & $0.007 *$ & 0.200 & 0.212 & 0.009 \\
\hline Prime\&Bond Elect vs Scotchbond Universal Bond & 0.387 & 0.245 & 0.807 & 0.435 \\
\hline Prime\&Bond Elect $v s$ All-Bond Universal & 0.438 & 0.015 & 0.151 & 0.285 \\
\hline Scotchbond Universal vs All-Bond Universal & 0.605 & $<0.001 *$ & 0.104 & 0.654 \\
\hline Clearfil Universal Bond vs Futurabond U & 0.413 & 0.223 & 0.663 & 0.107 \\
\hline
\end{tabular}

${ }^{\dagger}$ Comparions marked with an asterisk are statistically significant $(\mathrm{P}<0.01)$ 
A

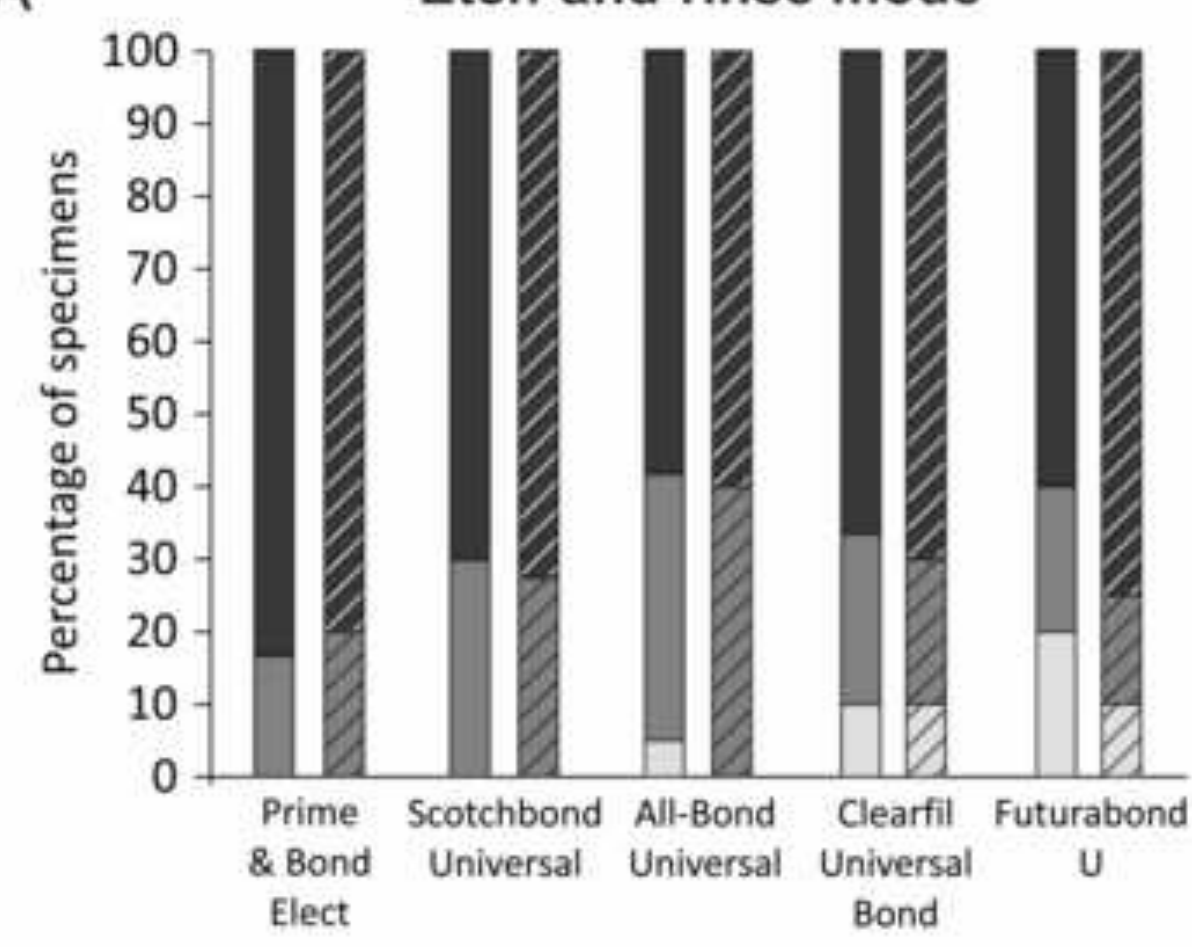

Mixed failure

Cohesive failure

$\square$ Adhesive failure
B

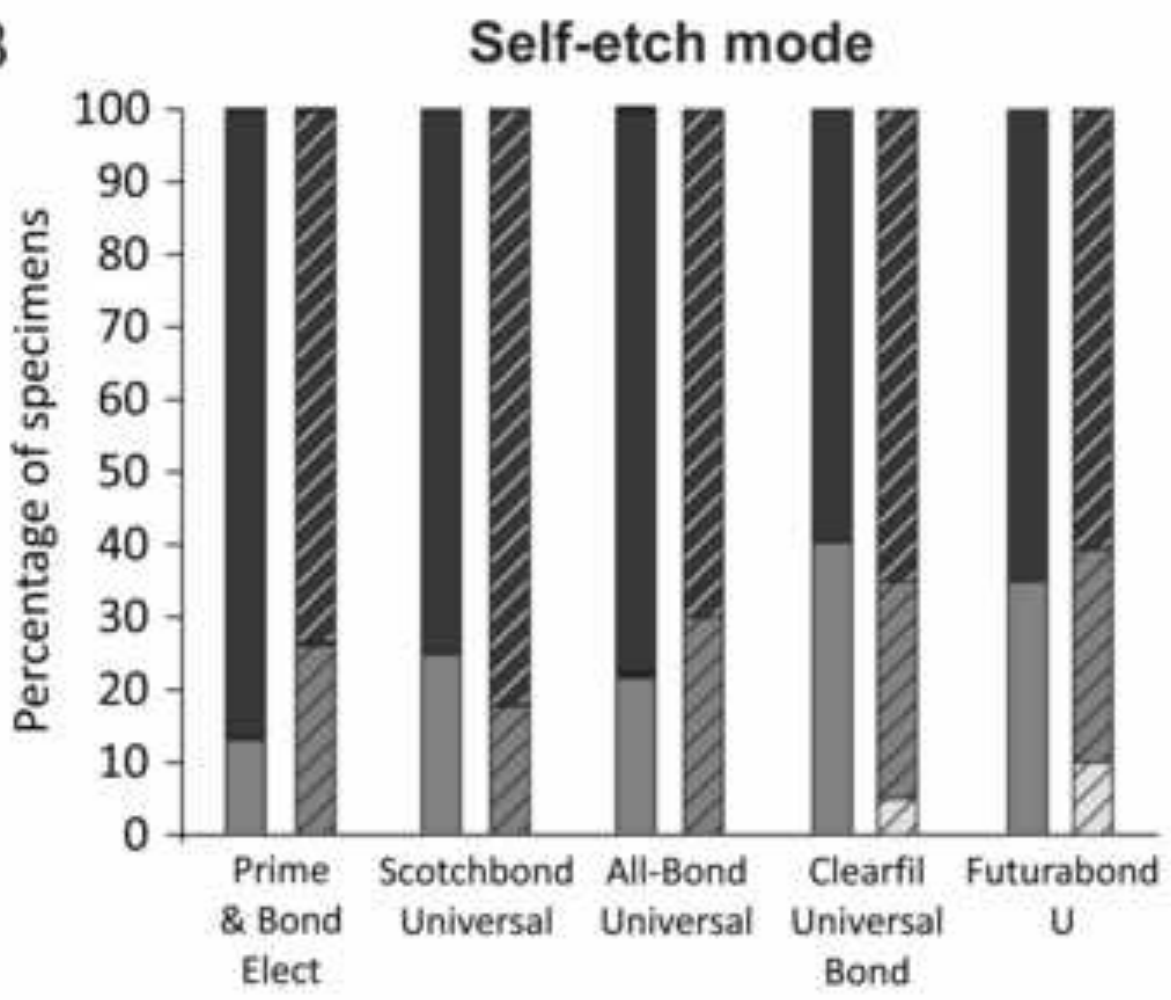

$\square$ No thermocycling

After thermocycling 


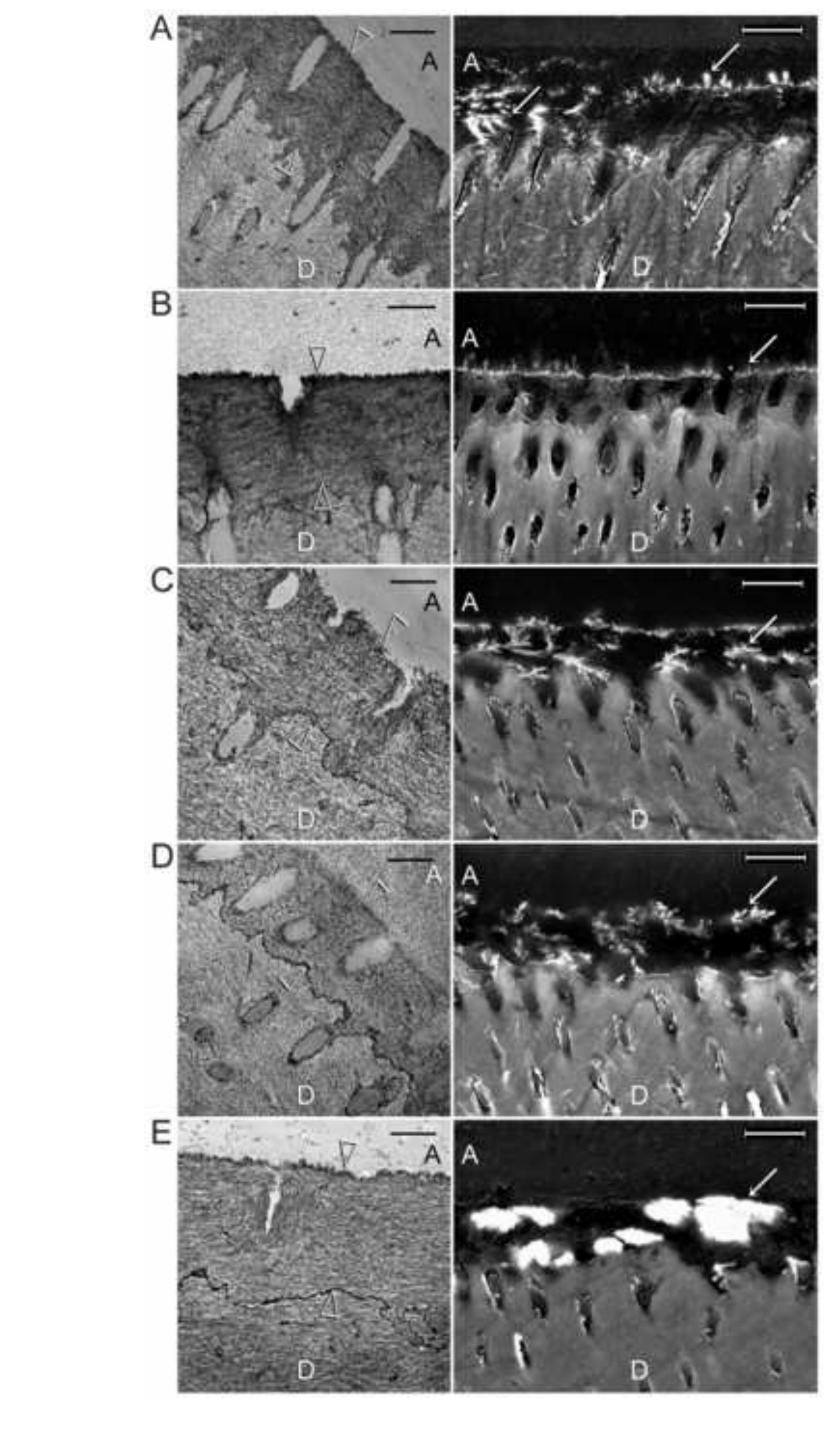

Figure 2

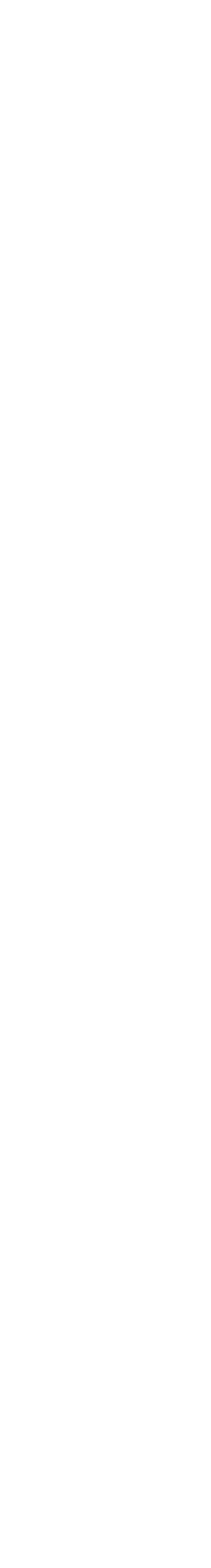

\section{Figure}

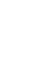
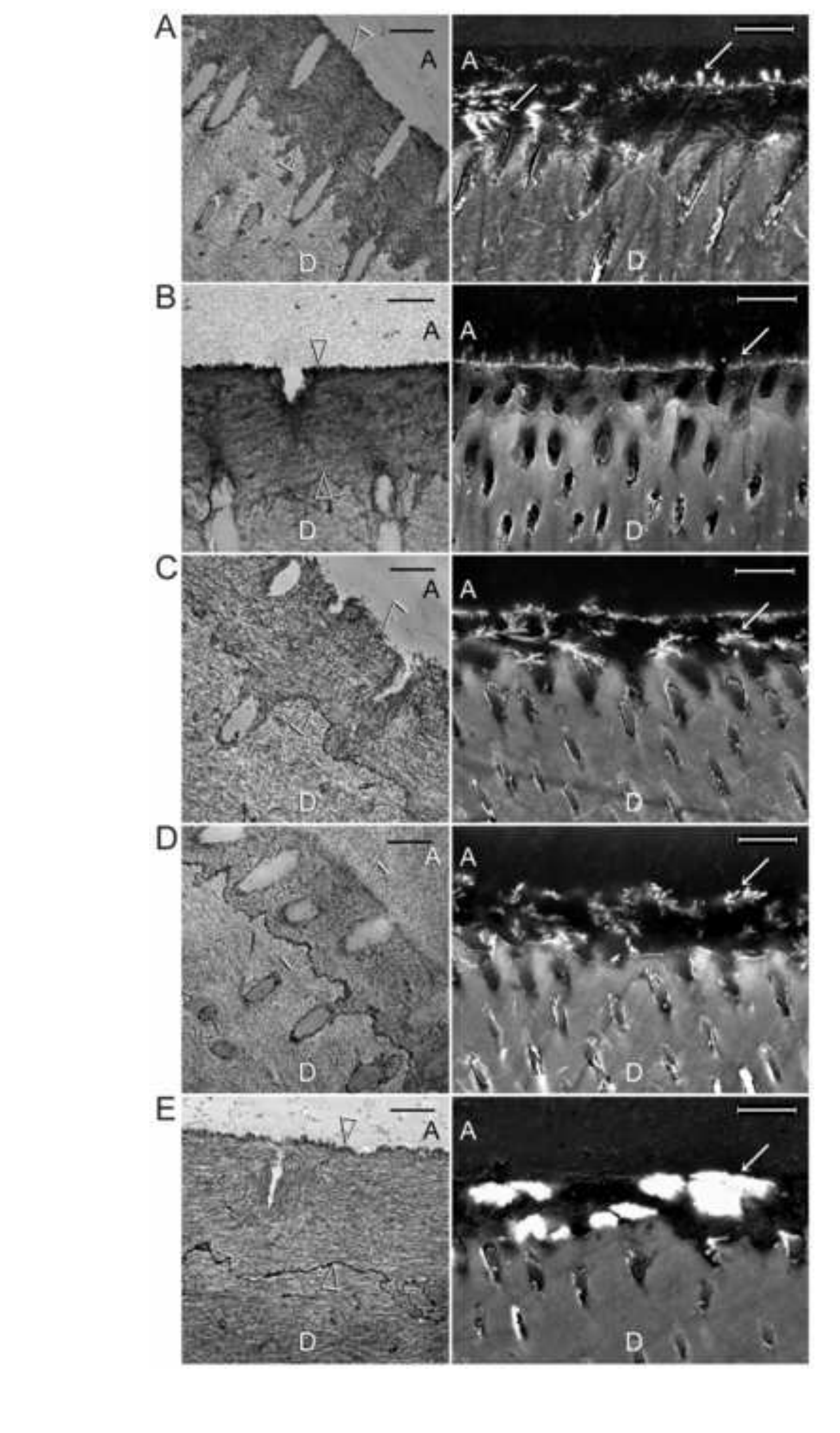
A

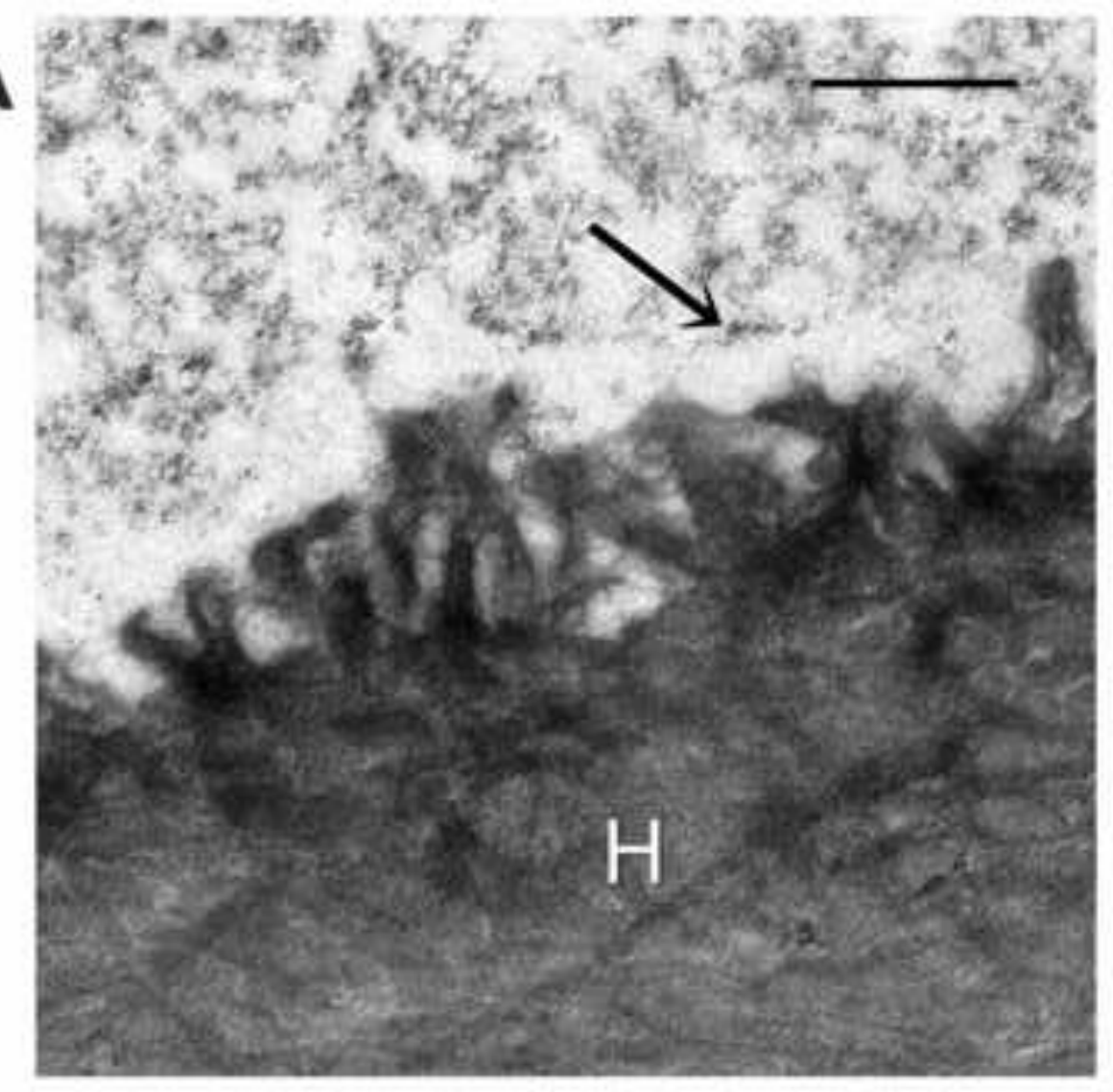

B
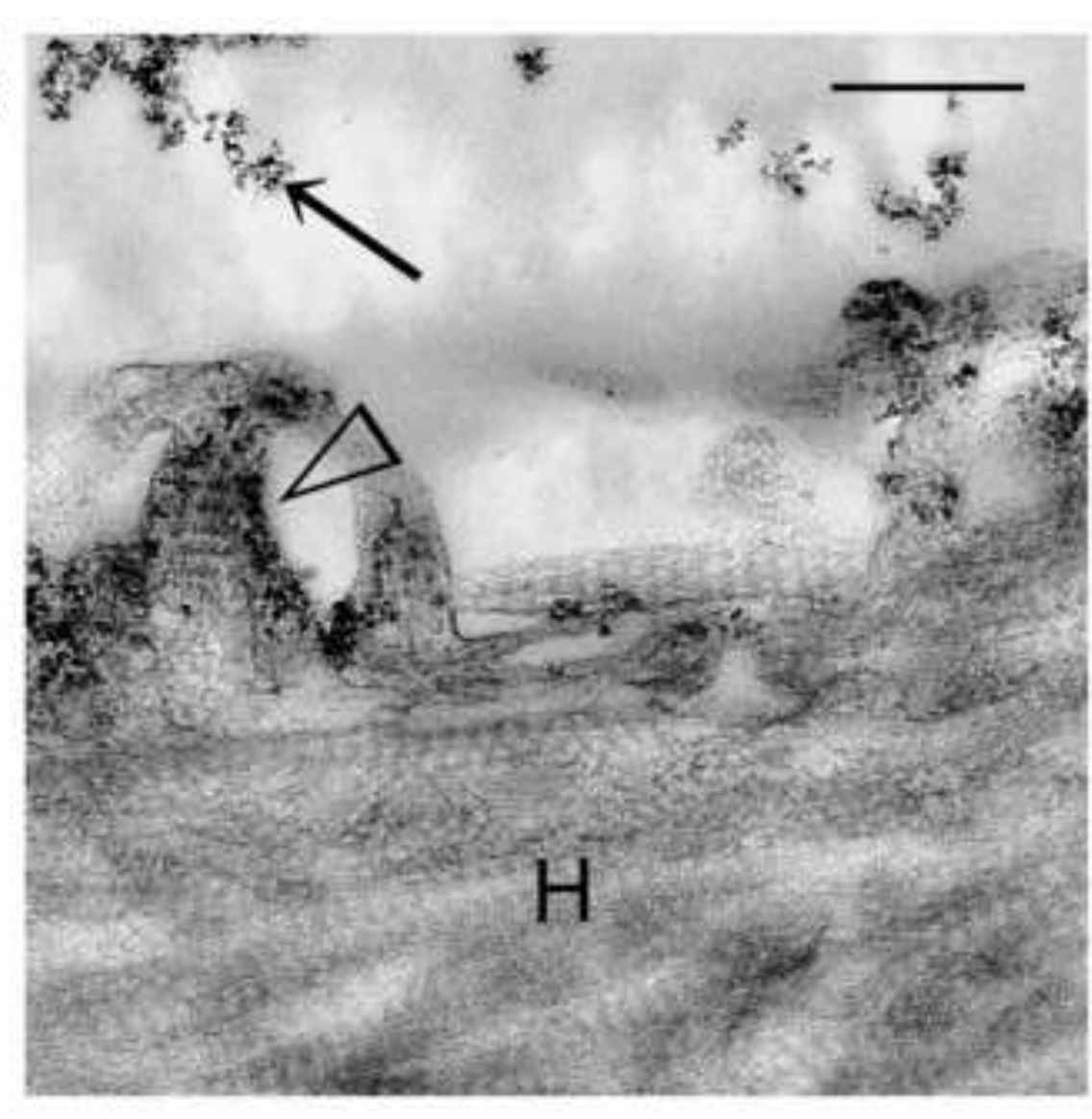

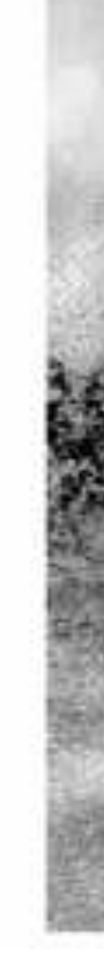




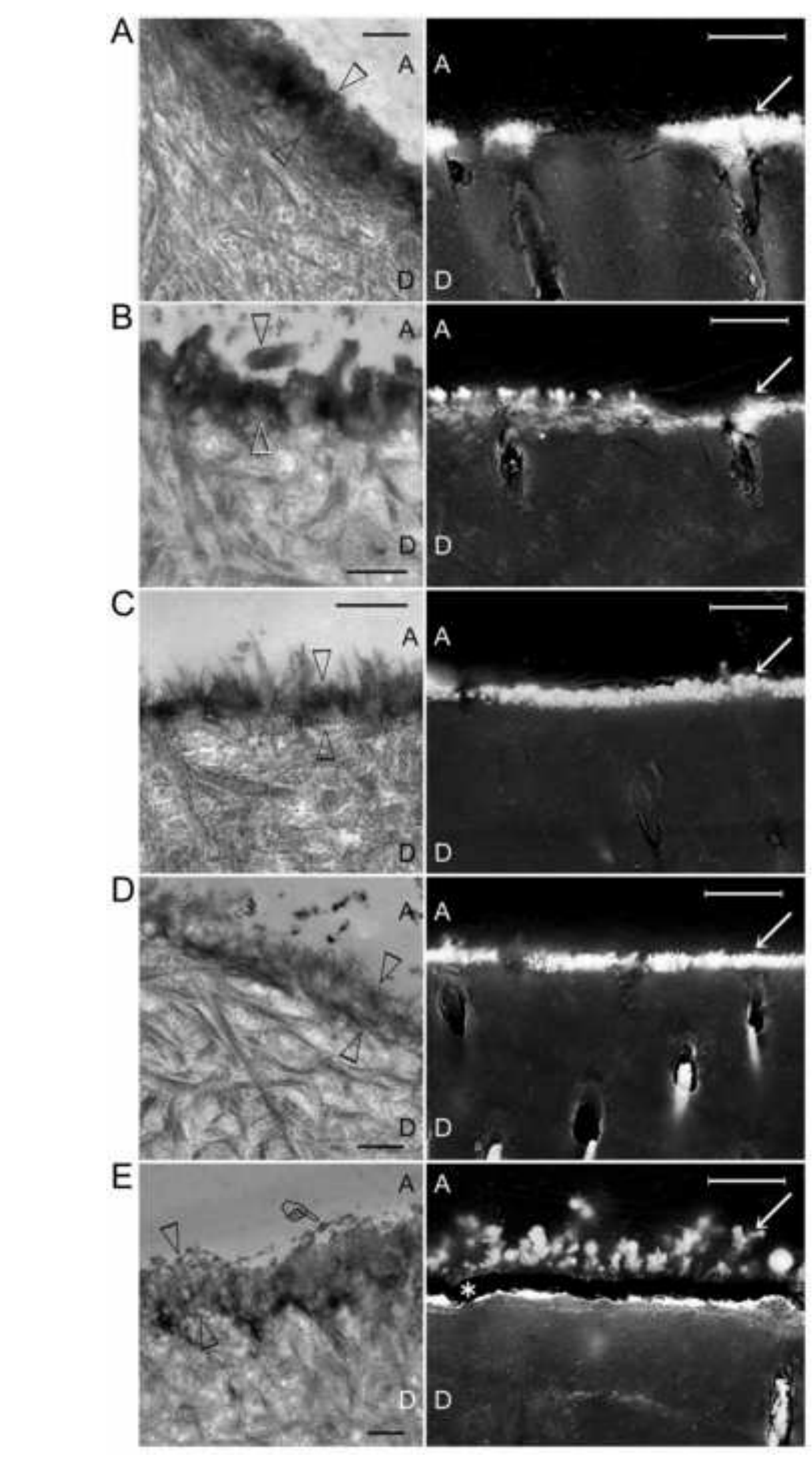

Figure 4
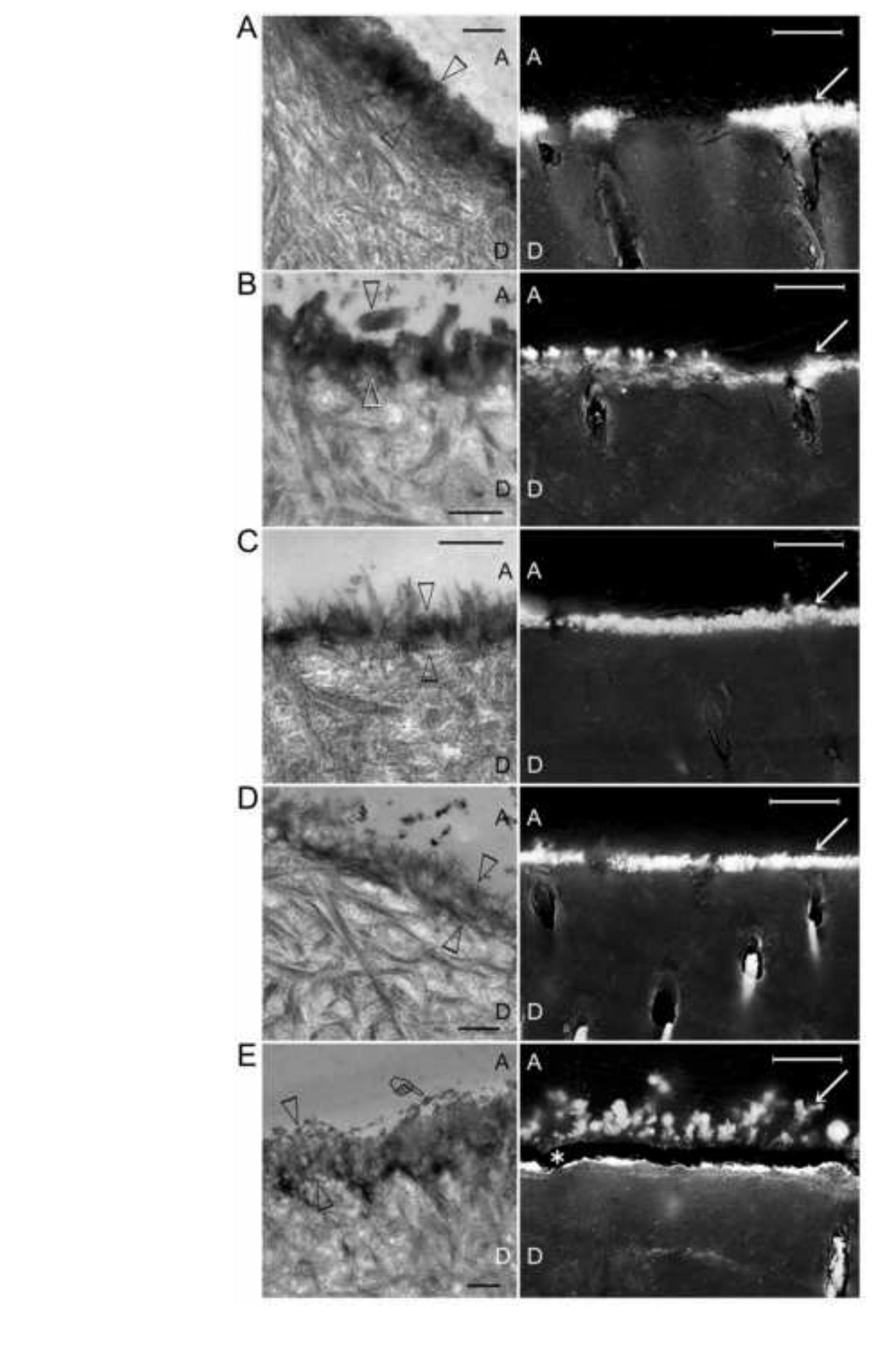

.

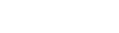

